\title{
Measured residual stress distributions for low and high heat input single weld beads deposited on to SA508 steel
}

\author{
J. A. Francis*, M. Turski and P. J. Withers
}

In steel welds, the development of residual stress is often complicated by the solid state phase transformations that occur upon cooling. Here the authors present bulk residual stress distributions, as measured by neutron diffraction, for the configuration of a single pass gas tungsten arc weld bead deposited on to a $20 \mathrm{~mm}$ thick SA508 steel substrate. Two specimens were manufactured, one with a low heat input $\left(1.2 \mathrm{~kJ} \mathrm{~mm}^{-1}\right)$ and another with a high heat input $\left(2 \cdot 4 \mathrm{~kJ} \mathrm{~mm}^{-1}\right)$. The resulting microstructures and residual stress distributions are discussed in terms of the differing thermal excursions across each weld. In regions that are austenitised during welding, the transformation strain on cooling is shown to compensate in part for thermal contraction strains. Accordingly, phase transformations in SA508 steel led to significant reductions in stress within the weld bead and much of the heat affected zone, while the highest tensile stresses were located immediately outside the heat affected zone boundary in the untransformed region.

Keywords: Bainite, Displacive transformation, Martensite, Phase transformation, Transformation strain, Welding parameters

\section{Introduction}

Many of the degradation mechanisms relevant to power plant components are exacerbated by tensile residual stresses. ${ }^{1}$ For example, residual stresses are known to enhance rates of stress corrosion cracking ${ }^{2}$ and creep, ${ }^{3,4}$ and they can also contribute to the development of fatigue cracks in and around weldments. ${ }^{5,6}$ Indeed, not only can residual stresses accelerate the onset of damage, they can also affect the tendency to fast fracture. ${ }^{7,8}$ Their consideration is therefore central to power plant integrity assessments and, as a consequence, there have been several attempts to incorporate residual stresses in to appropriate structural integrity assessment procedures. $^{9-11}$

Welding operations typically introduce substantial residual stresses into power plant components due to the highly localised and extreme manner in which heat is applied. The resulting high temperatures and thermal gradients give rise to spatial and temporal variations in thermal expansion and contraction, leading to nonuniform plastic flow of the thermally softened metal. The associated misfit strains often lead to near yield tensile stresses at room temperature, especially in the welding direction. There are, however, other phenomena that may influence the stresses that develop. In the case of transformable steels, for example, it is also known that

School of Materials, University of Manchester, Grosvenor Street, Manchester, M1 7HS, UK

*Corresponding author, email John.Francis@manchester.ac.uk solid state displacive phase transformations can have significant effects on residual stress distributions. ${ }^{12-14}$

There are relatively few studies that report measurements for the bulk residual stresses that exist in and around welds in thick section ferritic power plant steels. Notable exceptions include Smith et al., ${ }^{15}$ who reported the results of deep hole drilling measurements down the weld centreline for a butt weld in a ferritic thick walled pipe. While these measurements were extremely valuable, this configuration involved a large number of weld passes, and it was not possible to appreciate the way in which stresses were distributed around individual weld beads. Price et al. ${ }^{16}$ carried out measurements on single bead on plate deposits on $12 \mathrm{~mm}$ thick plates of a low alloy steel, made by gas metal arc welding. However, the reported neutron diffraction measurements comprised near surface line scans and, as such, the bulk residual stress distributions were not reported. Notwithstanding these contributions, there remains a pressing need for more information relating to the effects of solid state phase transformations on bulk residual stress distributions and, furthermore, an assessment of the extent to which welding parameters can affect the final state of stress.

Satoh tests, ${ }^{17,18}$ in which a testpiece is cooled between fixed grips, can reveal the extent to which phase transformations upon cooling are likely to affect the evolution of residual stress in the presence of constraint. ${ }^{13}$ Here, the authors first present the results of Satoh tests on matchstick sized coupons of SA508 grade 3 class 1 steel, as well as results for the filler metal that is 
used throughout the present study. It is worth noting at this point that SA508 steel is expected to undergo a displacive phase transformation when cooled from the austenite phase field at a rate that is representative of weld cooling cycles. ${ }^{19}$ The Satoh test results along with metallurgical analysis are then used to interpret residual stress distributions, as measured by neutron diffraction, for two single bead on plate deposits on $20 \mathrm{~mm}$ thick SA508 steel substrates, whereby one sample was made with a low heat input and the other with a high heat input.

The authors' primary objective has been to map the distribution of bulk residual stresses around individual weld beads, thereby establishing the relationship between the different microstructural zones that arise in a weld and the resultant residual stress distributions. By studying a simple weld geometry, the authors hope that the results will help to underpin future finite element weld models that incorporate phase transformations. At the present time, such models tend to include the volume expansion associated with the phase transformation, ${ }^{20}$ but neglect the anisotropic shear component. Furthermore, by studying the microstructures and weld stresses for single weld beads deposited with low and high heat inputs, the authors have attempted to bracket the expected range of behaviours for weld beads deposited on to SA508 steel.

\section{Experimental}

\section{Deposition of weld beads}

Two single bead on plate welds were made using the gas tungsten arc welding process; one at 'low' and one at 'high' heat input. In both cases direct current electrode negative polarity was used, with argon as the shielding gas. The power supply was of the transformer rectifier type, and it was coupled with an arc voltage controller so that adjustments to the arc length could be made, if necessary, during welding. The tungsten electrode was doped with 2 wt- $\%$ thoria, measured $3.2 \mathrm{~mm}$ in diameter, and had a ground conical tip with an included angle of $60^{\circ}$. The filler wire had a diameter of $1.2 \mathrm{~mm}$ and was introduced to the weld pool by a motorised feeder. Travelling during welding was achieved by holding the sample stationary, while translating the torch along a rail track.

In both cases the substrate plates were made from SA508 grade 3 class 1 steel, which is generally supplied in a quenched and tempered condition, with typical mechanical properties as listed in Table $1 .^{21}$ Table 2 includes the nominal compositions for both the SA508 substrate material as well as the low carbon SD3 filler material used in the experiments. Each of the plates was machined to the dimensions of $180 \times 120 \times 20 \mathrm{~mm}$ and then stress relieved before welding (so that any influence of machining stresses was eliminated) by heating to $600^{\circ} \mathrm{C}$ for $2 \mathrm{~h}$ in a vacuum furnace. The plates

Table 1 Typical mechanical properties for SA508 grade 3 , class 1 steel in the quenched and tempered condition $^{21}$

\begin{tabular}{lll}
\hline $\begin{array}{l}0.2 \% \text { proof } \\
\text { stress, MPa }\end{array}$ & $\begin{array}{l}\text { Ultimate tensile } \\
\text { strength, MPa }\end{array}$ & $\begin{array}{l}\text { Elongation to } \\
\text { failure, \% }\end{array}$ \\
\hline 450 & $560-600$ & 25 \\
\hline
\end{tabular}

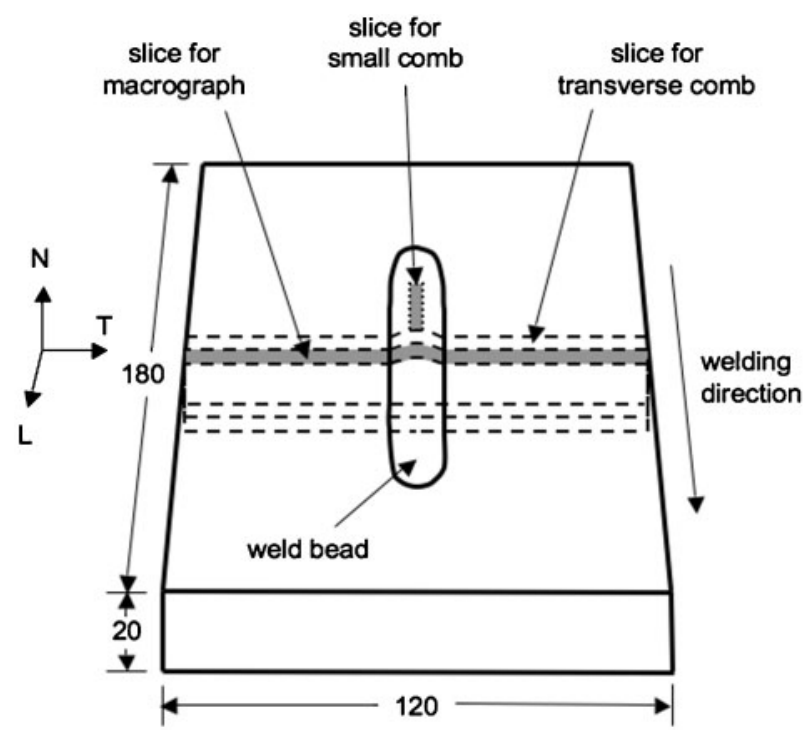

1 Schematic representation of bead on plate specimen, showing location at which macrograph slices were extracted, together with comb specimens for neutron diffraction measurements: longitudinal (L), transverse (T) and normal ( $N$ ) orientations are highlighted; all dimensions are in millimetres

themselves were not heavily restrained during welding. Instead, the thickness of the plate was chosen to be sufficient to provide significant material constraint for the weld bead, while also not being so thick as to make detailed neutron strain mapping impractical. This decision was made because externally applied restraint can be difficult to express in terms of boundary conditions in numerical models for residual stress development in welding.

Table 3 lists the nominal welding parameters used for plates 1 and 2 . These conditions were thought to provide representative lower $\left(1 \cdot 2 \mathrm{~kJ} \mathrm{~mm}^{-1}\right)$ and upper $\left(2 \cdot 4 \mathrm{~kJ} \mathrm{~mm}^{-1}\right)$ bounds respectively in heat input for the single bead on plate configuration using gas tungsten arc welding on $20 \mathrm{~mm}$ thick steel plates. The values given for the heat input are nominal and do not account for the arc efficiency. However, during welding, values of variables such as the arc voltage and welding current were monitored and recorded to ensure that the welding conditions were closely aligned with those in Table 3.

\section{Metallography on welded specimens}

One slice approximately $5 \mathrm{~mm}$ in thickness was extracted from each bead on plate sample (Fig. 1) for the purpose of metallographic analysis. These slices were mechanically polished to a $1 \mu \mathrm{m}$ surface finish, and etched in $2 \%$ nital for $\sim 15 \mathrm{~s}$. The microstructures were then observed under an optical microscope, and digital photographs were captured from the different metallurgical zones that arise across a single weld bead.

Table 2 Nominal compositions for SA508 steel plates and weld filler material, wt-\%

$\mathrm{N}$, C Si $\mathrm{MnNi} \quad \mathrm{Cr}$ Mo $\mathrm{V}$ Al $\mathrm{Cu}$ ppm $\mathrm{Fe}$

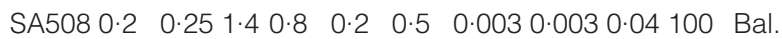

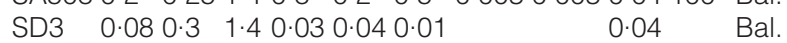
Filler 


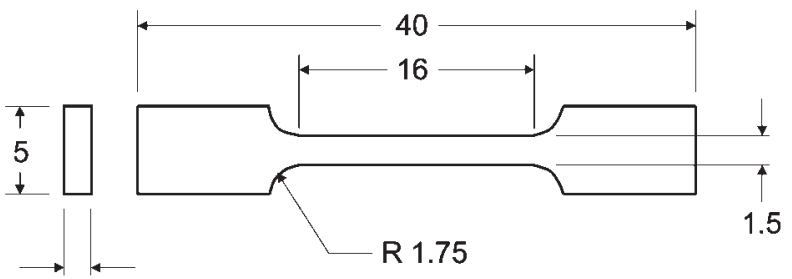

1.5

2 Nominal dimensions of coupons used in Satoh test experiments: all dimensions in millimetres

\section{Hardness testing on welded specimens}

Hardness testing was carried out on the macrograph slices from both bead on plate samples in the regions near to the weld bead so that, in combination with the optical microscopy, the dimensions of the different metallurgical zones could be determined. In all cases, a Vickers indenter was used in conjunction with a $0.5 \mathrm{~kg}$ load. Traverses were carried out in a straight line with measurements at intervals of $0.25 \mathrm{~mm}$, starting from within the fusion zone, and heading in to the heat affected zone (HAZ) and parent material, following a path down the weld centreline. The traverses spanned approximately 8 to $10 \mathrm{~mm}$.

\section{Satoh testing on matchstick sized coupons}

Satoh tests ${ }^{17,18}$ were carried out on SA508 steel coupons, as well as on SD3 all-weld-metal specimens, in order to assist in understanding how localised phase transformations would influence the final state of stress in the single bead on plate weld deposits. In each case, the test coupons were prepared by electric discharge machining to the dimensions shown in Fig. 2. The parent material was tested in the as received condition, while the allweld-metal coupons were extracted from a weld metal pad. This pad was built by depositing several layers of overlapping weld beads to a height of approximately $20 \mathrm{~mm}$ above the surface of an SA508 base plate, and the all-weld-metal coupons were extracted from the upper layers of the pad, so that the effects of dilution by the base plate could be considered to be negligible.

In the Satoh tests, test coupons (Fig. 2) were first heated free from constraint at $10^{\circ} \mathrm{C} \mathrm{s}^{-1}$ by passing an electric current through the sample. During testing, the temperature at the centre of each sample was monitored with an $\mathrm{R}$ type thermocouple that was spot welded to the surface of the coupon. Once the specimen reached the specified temperature, it was held at this temperature for $10 \mathrm{~s}$, after which the coupon was allowed to cool under fixed grip constraint while the stress was monitored.

The rationale behind the Satoh tests was to simulate the accumulation of stress on cooling from two locations; one being within the austenitised region of a

Table 3 Summary of nominal welding parameters for each specimen

\begin{tabular}{|c|c|c|c|c|c|}
\hline Plate & $\begin{array}{l}\text { Heat } \\
\text { source } \\
\text { power, V }\end{array}$ & $\begin{array}{l}\text { Welding } \\
\text { speed, } \\
N \mathrm{~mm} \mathrm{~min}^{-1}\end{array}$ & $\begin{array}{l}\text { Preheat } \\
\text { temperature, } \\
1 \text { C }\end{array}$ & $\begin{array}{l}\text { Wire feed } \\
\text { speed, } \\
\mathrm{mm} \mathrm{min}^{-1}\end{array}$ & $\begin{array}{l}\text { Heat } \\
\text { input, } \\
\mathrm{kJ} \mathrm{mm}^{-1}\end{array}$ \\
\hline 1 & 1500 & 75 & 150 & 1000 & 1.2 \\
\hline 2 & 2000 & 50 & 150 & 1000 & $2 \cdot 4$ \\
\hline
\end{tabular}

weld and the other residing just outside the austenitised zone. Suitable peak temperatures for this purpose were chosen in accordance with the continuous cooling transformation diagram given for SA508 grade 3, class 1 steel in Ref. 19. For the austenitised samples the peak temperature was chosen to be $850^{\circ} \mathrm{C}$, while for the other coupons the peak temperature was chosen to be $680^{\circ} \mathrm{C}$. Two cooling rates were investigated for the austenitised specimens in both the parent plate and weld metal, namely 10 and $50^{\circ} \mathrm{C} \mathrm{s}^{-1}$. The cooling rate for all of the specimens heated to $680^{\circ} \mathrm{C}$ was $10^{\circ} \mathrm{C} \mathrm{s}^{-1}$.

Of course all of the weld metal is necessarily austenitised in a single pass weld. Nevertheless, it is still worthwhile comparing the accumulation of stress in the weld metal on cooling with the case where no phase transformations take place as a benchmark. This explains why a Satoh test was carried out on an all-weld-metal coupon heated only to $680^{\circ} \mathrm{C}$.

\section{Neutron diffraction stress measurements on welded plates}

Strain mapping by neutron diffraction was carried out on both welded plates at two monochromatic (reactor) sources, namely the STRESS-SPEC beam line at FRM II in Germany and the SALSA beam line at ILL in France. In all cases, strain measurements were made over a half plane, orientated normal to the welding direction, and located at the midlength of the weld bead. In other words, symmetry was assumed about the weld centreline in order to allow a greater resolution in the stress measurements within the time available. At both sources, all measurements were made using the 211 crystal reflection, with the wavelength of the neutrons being approximately $1.672 \AA$ at FRM II and 1.594 $\AA$ at SALSA. These wavelengths resulted in scattering angles close to $90^{\circ}$, thereby giving essentially cuboidal gauge volumes.

The first array of measurements on each plate was made at FRM II, and comprised the locations shown in Fig. $3 a$. The objective with such an array was to capture the stress field acting over the entire half plane. Here, the nominal dimensions of the gauge volumes for the measurements of the longitudinal component of strain (parallel to the welding direction) were $3 \times 3 \times 3 \mathrm{~mm}$, while for the transverse strains and normal strains they were $3 \times 3 \times 10 \mathrm{~mm}$. A second array of measurements was then carried out at SALSA as illustrated in Fig. $3 b$. In this case the objective was to capture greater detail in the stress distributions in the vicinity of the weld bead, noting that the stresses were likely to vary primarily with distance from the bead. The nominal gauge volumes for the measurements of the longitudinal component of strain were $2 \times 2 \times 2 \mathrm{~mm}$, while for the transverse and normal strains they were $2 \times 2 \times 10 \mathrm{~mm}$.

\section{Determination of strain free lattice parameter $\boldsymbol{d}_{\mathrm{o}}$}

Neutron diffraction provides estimates for strain in a given direction by comparing the lattice spacing that is measured in the location of interest $d$, with the lattice spacing that is measured in an equivalent volume of material that is free of elastic strain (this strain free lattice spacing is referred to as $d_{0}$ ). Since welds introduce gradients in both microstructure and strain history to a component, it is recommended that position dependent values for $d_{0}$ are determined. ${ }^{22}$ In the present work, far field values (i.e. at locations away from the heat- and 

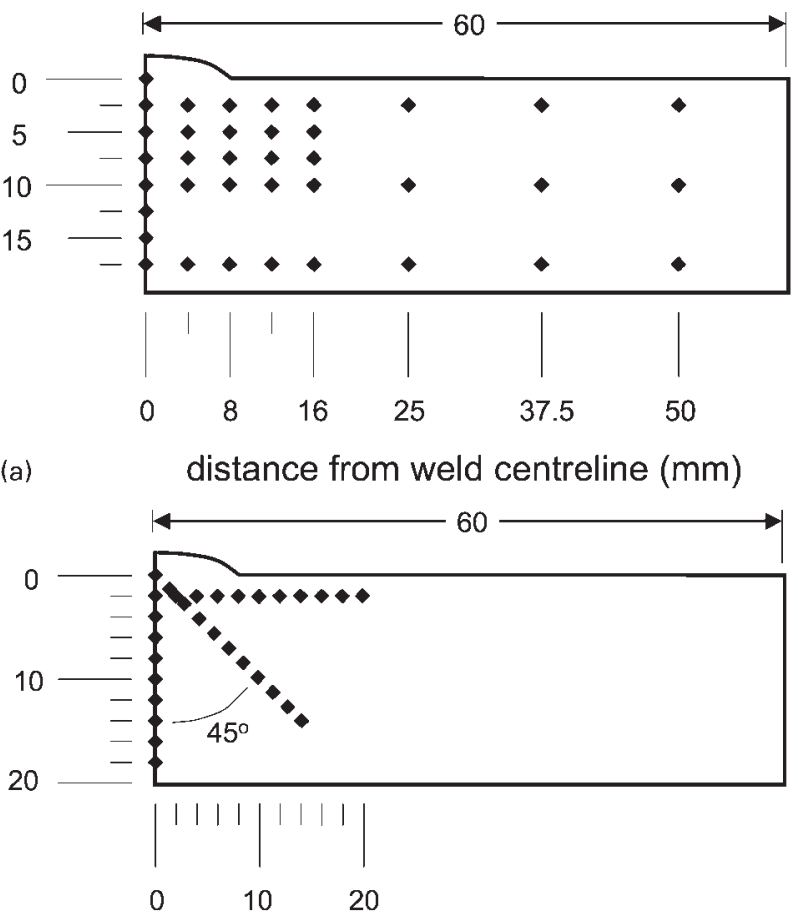

(b)

distance from weld centreline $(\mathrm{mm})$

3 Measurement locations for single bead on plate specimens, all on half plane at midlength position along the welds, showing a locations for determination of stress distribution over entire half plane at FRM II and $b$ higher resolution measurements near to weld bead (at SALSA): all dimensions are in millimetres

strain-affected zones of the sample) $)^{23}$ were obtained by averaging three measurements of the 211 diffraction peak made at one of the underside corners of each sample plate. Given that when the gauge volume is near to a corner it is beside three free surfaces, and that the ratio of the plate width to the weld width was large, these locations should have been effectively free of stress. In each case, one measurement was made in the direction of each of the three coordinate axes of the plate. From these measurements, it was found that there was no significant difference in the value of $d_{0}$ recorded as a function of orientation within the plate.

The variations in $d_{0}$ that arise between locations in the unaffected parent material and locations within the heatand strain-affected zones or the weld metal were accounted for in the following way. After the neutron measurements for $d$ spacings had been completed, two stress free comb specimens ${ }^{23}$ were extracted from each plate at the locations shown in Fig. 1. In all cases, the comb specimens were prepared from $4 \mathrm{~mm}$ thick slices of material, the comb teeth had cross-sections measuring $4 \times 4 \mathrm{~mm}$, and the extraction was carried out by electric discharge machining. The final configuration of these comb specimens is shown in Fig. 4a. One type of comb was prepared from a slice of material that was orientated transversely to the welding direction, and this was extracted approximately at the midlength position of the weld bead. This 'transverse' comb was designed primarily to capture variations in $d_{0}$ with distance from the weld centreline. For each plate, a second and smaller 'longitudinal' comb was also extracted from a slice of material that was orientated parallel to the welding direction, and transverse comb

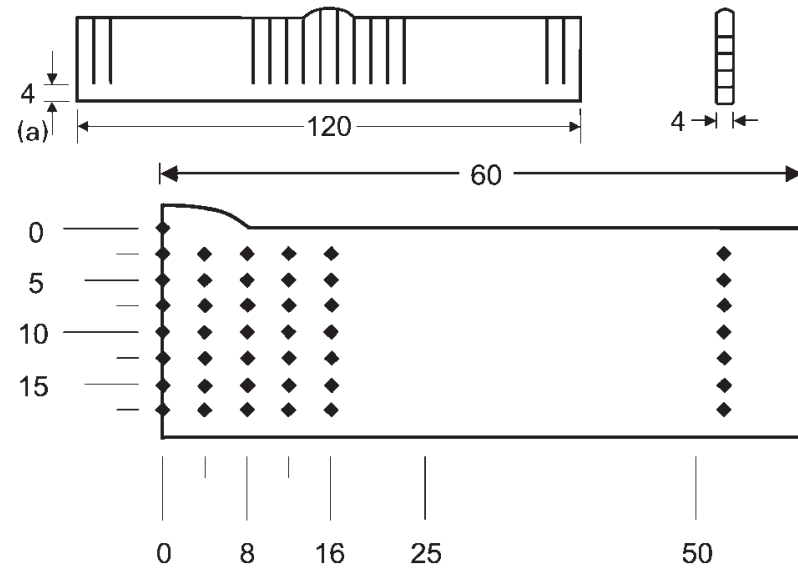

(b)

distance from weld centreline $(\mathrm{mm})$

4 Schematic representations of a configuration of comb specimens when looking parallel to welding direction and $b$ locations for $d_{0}$ measurements on measurement half plane: all dimensions are in millimetres

that was in the same plane as the weld centreline. The longitudinal combs were designed to capture variability in $d_{0}$ with depth through the welded plates.

The positions at which $d_{0}$ measurements were made are shown in Fig. 4b. Measurements were made with a $2 \times 2 \times 2 \mathrm{~mm}$ gauge volume being immersed, where possible, near to the end of the comb teeth, since this is where the relief of macroscopic stresses is most effective. Consequently, values for $d_{0}$ at positions on the weld centreline were obtained from the longitudinal comb specimen, while values for positions beside the top surface of the plate were measured on the transverse comb. Additional values for $d_{0}$ were obtained by making measurements along the length of the teeth on the transverse comb. In principle, these additional measurements need to be treated with care because of the residual constraint. However, the authors checked the effectiveness of the stress relaxation as a function of distance along the comb teeth by comparing the measurements for $d_{0}$ on the weld centreline, as obtained from the small comb, with values that were obtained by traversing along the central tooth on the transverse comb. The discrepancies were found to be comparable to the uncertainties in $d_{0}$.

\section{Metallurgical analysis}

Figure 5 shows optical photographs that were captured from plate 1 (low heat input). A macrograph of this sample is shown in Fig. $5 a$, with the weld bead appearing in the top left corner of the image. Successive images then correspond to micrographs taken from the different metallurgical regions that arise across the HAZ of a ferritic steel weld. These regions have been described previously ${ }^{14,24}$ and are, in order of increasing peak temperature, the over tempered zone; the intercritical or partially austenitised HAZ (ICHAZ); the fine grained HAZ (FGHAZ); and finally the coarse grained HAZ (CGHAZ) which is beside the fusion zone itself. Since both plates were stress relief heat treated before welding, there was no microstructural evidence of an over tempered zone in either sample. 


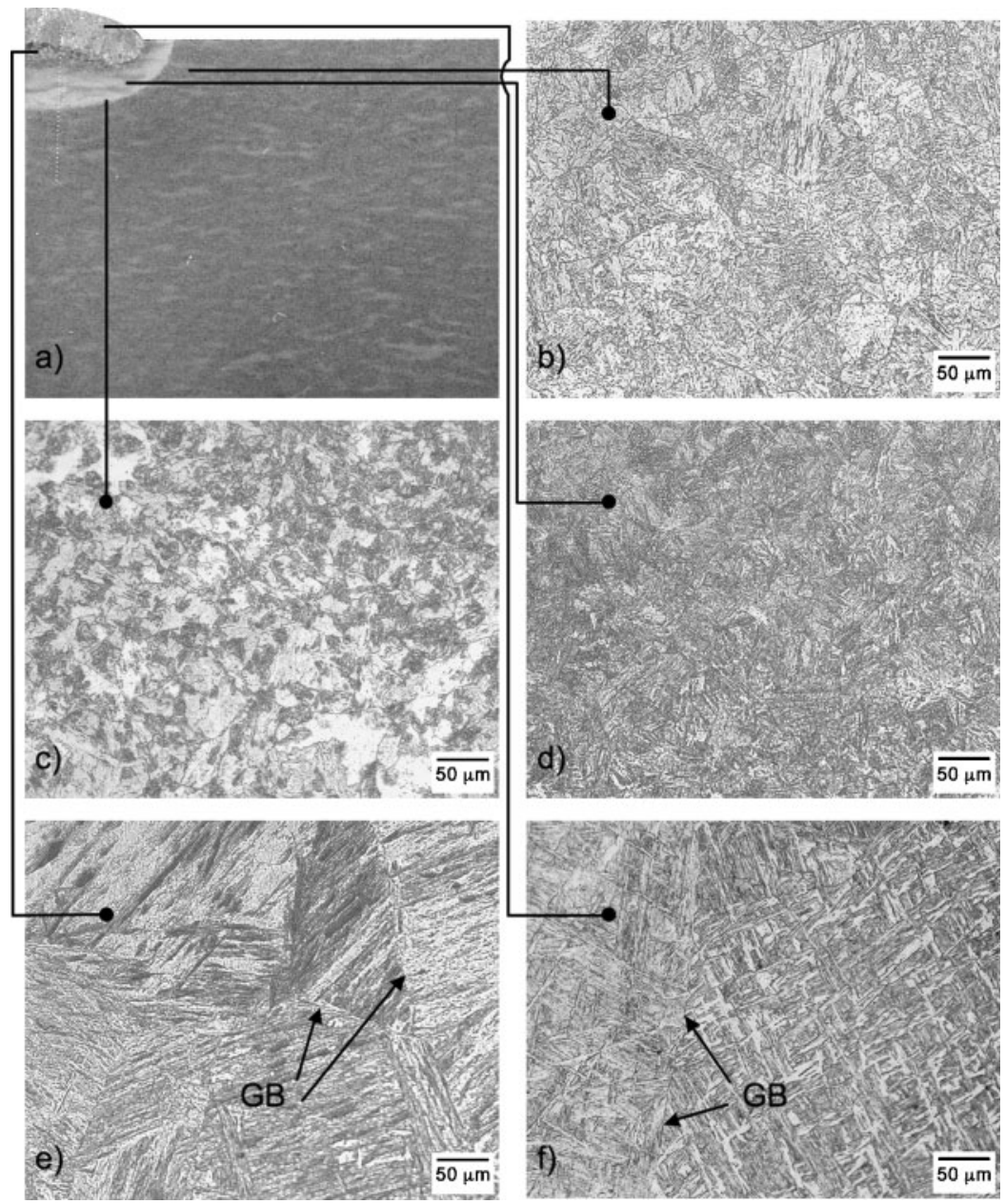

5 Optical micrographs from plate 1 showing a low magnification image of $20 \mathrm{~mm}$ thick plate and typical microstructures for $b$ stress relieved parent material, $c$ ICHAZ, $d$ FGHAZ, $e$ CGHAZ and $f$ fusion zone: in $e$ and $f$ preserved austenite grain boundaries are highlighted (GB)

At all locations more than a few millimetres from the weld bead, the microstructure is typical of stress relieved parent material (Fig. 5b). As we approach the weld region we first encounter the ICHAZ (Fig. 5c), which is characterised by a mixture of light etching regions, which correspond to ferrite that did not transform to austenite during the welding thermal cycle, as well as some darker etching regions which were austenitised. Those regions that were austenitised will have been enriched in carbon and, as such, may have transformed to pearlite on cooling. ${ }^{25}$ Other possible transformation products include bainite and a brittle martensiteaustenite constituent. ${ }^{26}$ While the ICHAZ can in itself be clearly identified, the transformation products within the austenitised regions of the ICHAZ are often difficult to resolve with optical microscopy.

The FGHAZ (Fig. 5d) and CGHAZ (Fig. 5e) are close enough to the fusion line to be fully austenitised during the welding thermal cycle. The transformed microstructures in these regions generally resembled bainite in both samples. However in the CGHAZ for plate 1, which was manufactured using the low heat input condition, there was also evidence of martensite. The principal features of the mixed bainitic-martensitic microstructures in plate 1 are apparent in Fig. 5e, which shows evidence of preserved austenite grain boundaries and the formation of plate-like structures. Here, the lighter regions are likely to be martensite while dark etching is indicative of the precipitation of carbides and the formation of bainite. Finally, the fusion zone (Fig. 5f) was found to have preserved prior austenite columnar grain boundaries, with the transformed microstructure having a mottled or interwoven appearance that is typical of intragranularly nucleated acicular ferrite.

While the microstructures that were seen in each sample generally appeared to be similar, the extent of the HAZ's differed significantly, which is unsurprising given the different heat inputs. The broadening of the HAZ with increasing heat input is evident in the results of the hardness traverses (Fig. 6). Here the variation in hardness at the weld centreline is plotted against the depth from the top surface of the plate. It can be seen that in both plates, the hardness of the parent material well below the weld is relatively constant and repeatable at approximately $200 \mathrm{HV0} \cdot 5$; in these regions the microstructures resembled stress relieved base material. As the weld is approached the hardness begins to increase at approximately $4 \mathrm{~mm}$ from the top plate surface in plate 1 , and $6 \mathrm{~mm}$ from the top plate surface in plate 2 . The characteristic dip in hardness that is associated with an over tempered zone is not evident in either sample. Instead, sudden increases in hardness correspond to the transition from stress relieved parent material to the ICHAZ. Further increases in hardness are seen moving from the ICHAZ into the fully austenitised FGHAZ and 
CGHAZ. Upon moving into the fusion zone the hardness is observed to fall somewhat.

The increases in hardness that are seen across the HAZ are a result of the formation of untempered bainitic-martensitic microstructures, which have a higher hardness than stress relieved parent material. The weld metal has a lower hardness than most regions within the HAZ due to the utilisation of a filler metal with a lower carbon concentration (Table 2). In both samples, the highest hardnesses appear to arise within the CGHAZ, which may be related to local increases in hardenability associated with coarser austenite grains. Furthermore, the higher hardness in the CGHAZ for plate 1 , when compared to plate 2 , indicates that a higher volume fraction of martensite was present in this low heat input weld. Nevertheless, the combined results from the optical microscopy and hardness testing suggest that, on the weld centreline, the outer boundary of the HAZ in plate 1 is approximately $4 \mathrm{~mm}$ from the top plate surface while in plate 2 the outer boundary is approximately $6 \mathrm{~mm}$ from the top plate surface.

\section{Influence of transformation strains on residual stress}

The results of the Satoh tests are shown in Fig. 7. In Fig. $7 a$ it can be seen that, when an SA508 parent material coupon is heated to $680^{\circ} \mathrm{C}$ and then constraint is applied, the accumulated stress increases monotonically on cooling to room temperature. At the commencement of cooling, the stress increases almost linearly with decreasing temperature until the yield stress is approached, at which point further increases in stress become more gradual. Finally, the residual stress at room temperature is commensurate with the room temperature yield stress $(\sim 450 \mathrm{MPa})$.

In contrast, the behaviour of the austenitised parent material coupons is quite different. Upon cooling from $850^{\circ} \mathrm{C}$, the stresses quickly reach the yield stress of austenite which, from the figure, appears to be approximately $50 \mathrm{MPa}$ at $800^{\circ} \mathrm{C}$. Beyond this point, the stresses still increase but at a slower rate, until the point is reached where a phase transformation commences. At approximately $600^{\circ} \mathrm{C}$, the stresses in both coupons begin to decrease as the transformation strains associated with the formation of bainite compensate for the accumulated thermal contraction strains. (While published values for the bainite start temperature are closer to $550^{\circ} \mathrm{C}$ for SA508 steel, ${ }^{19}$ it is worth noting that the start temperature is likely to increase in the presence of stress.) Interestingly, the compensation at $600^{\circ} \mathrm{C}$ is more pronounced in the specimen cooled at $10^{\circ} \mathrm{C} \mathrm{s}^{-1}$ than for that cooled at $50^{\circ} \mathrm{C} \mathrm{s}^{-1}$, which suggests that the slow cooled specimen is forming a greater proportion of bainite. However, at a later stage, a further decrease in stress is seen for the fast cooled specimen at approximately $400^{\circ} \mathrm{C}$, which corresponds closely with the martensite start temperature. ${ }^{19}$ Finally, when the transformations in each coupon have exhausted, the stresses increase once again as thermal contraction strains accumulate until room temperature is reached.

There are some important points that are raised by the results in Fig. 7a. First, it is evident that the samples that were heated to $850^{\circ} \mathrm{C}$ have lower room temperature residual stresses than the sample that was heated to
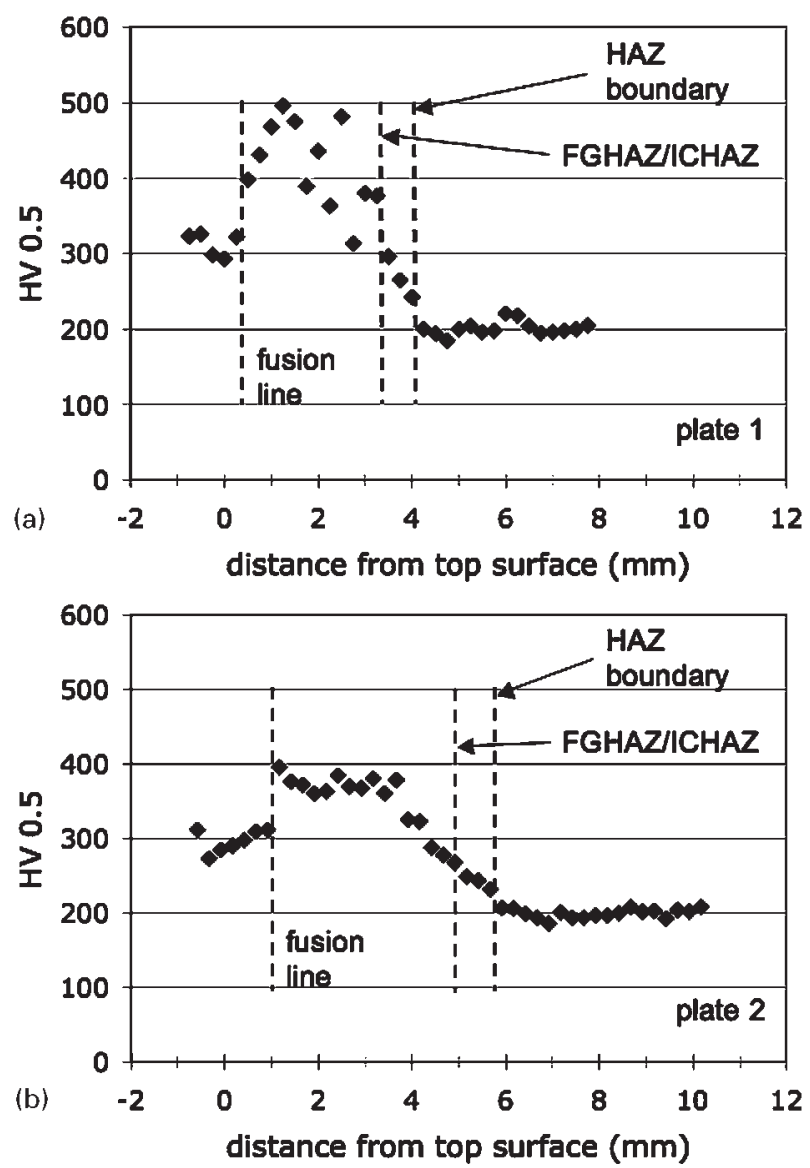

6 Vickers hardness profiles with depth at weld centreline for $a$ low heat input weld (plate 1) and $b$ high heat input weld (plate 2): extent of fusion zone and HAZ are shown, as determined by optical microscopy; boundary between fully austenitised and intercritical HAZ is also highlighted; origin of coordinate system corresponds to point that resided on top (welded) surface of plate before deposition of bead

$680^{\circ} \mathrm{C}$, despite the fact that the thermal contraction strain that must be accommodated would be larger with a higher hold temperature. Second, among the austenitised samples, it can be seen that the residual stress at room temperature is lower for the sample cooled at $50^{\circ} \mathrm{C} \mathrm{s}^{-1}$ than it is for the sample cooled at $10^{\circ} \mathrm{C} \mathrm{s}^{-1}$. In the fast cooled sample, the results suggest that a higher volume fraction of martensite has formed, with the transformation progressing at lower temperatures. As a result there was reduced scope for the accumulation of stress on cooling once the transformation had exhausted.

The behaviour of the filler material (Fig. 7b) is broadly similar to the parent material, but there are also notable differences. First, the room temperature residual stress is lower $(\sim 350 \mathrm{MPa})$ in the sample heated to $680^{\circ} \mathrm{C}$ than it is in the corresponding SA508 coupon $(\sim 450 \mathrm{MPa}$ in Fig. $7 a)$. This is likely to be a consequence of the low carbon filler metal having a lower yield stress than untempered SA508 steel. This is consistent with the results in Fig. 6, which show the weld metal having a lower hardness than the adjacent HAZ. Second, it can be seen that the phase transformations in the all-weld-metal coupons have had a less significant effect on the room temperature residual 

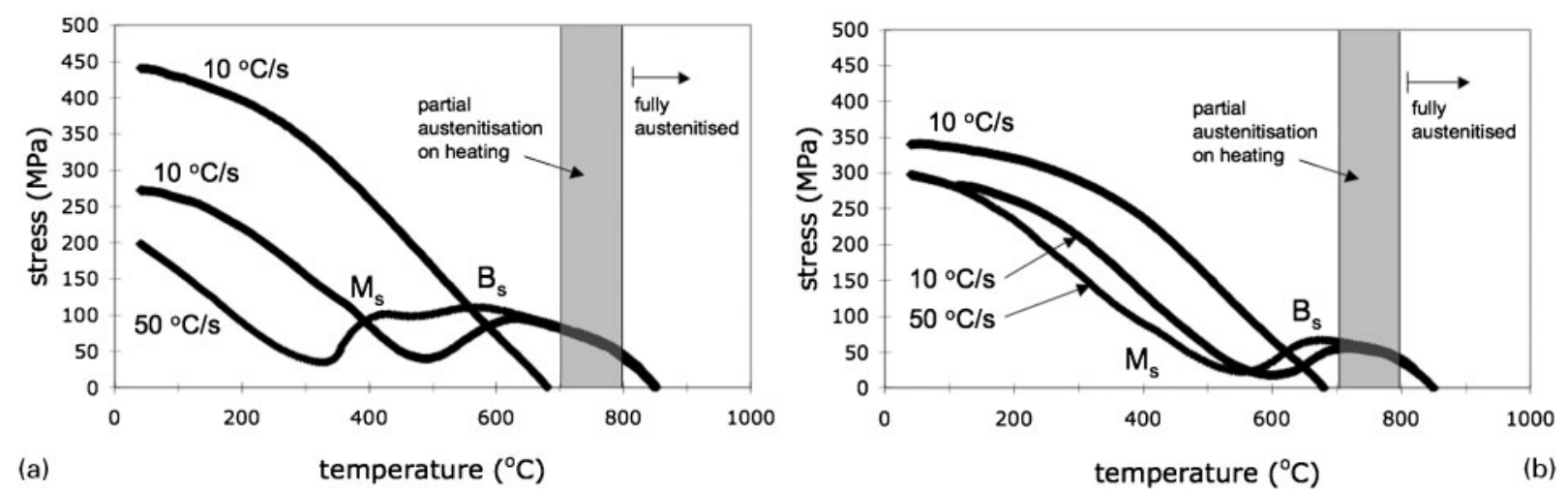

7 Results of Satoh tests ${ }^{17,18}$ on a SA508 steel coupons and $b$ SD3 all-weld-metal coupons cooled under constraint from different peak temperatures; it can be seen that, for coupons heated to $850^{\circ} \mathrm{C}$, transformation strains on cooling partly compensate for thermal contraction strains; accumulated stress at room temperature is greater for material heated to $680^{\circ} \mathrm{C}$

stresses than is the case for the parent material. This observation is not unexpected when considering a filler material with lower levels of alloying, since the formation of ferrite and bainite on cooling will generally be faster when the concentrations of alloying elements decrease, ${ }^{27}$ and this can have the overall effect of raising the temperature range over which transformations take place. When considering the weld stresses below in the light of the Satoh tests, it should be borne in mind that the weld beads in the single bead on plate deposits would have been diluted by the parent material. This will result in the behaviour of the weld beads being more closely aligned with the behaviour of the parent material than might be inferred directly from Fig. $7 b$.

\section{Weld residual stress distributions}

Figure 8 shows plots of the bulk residual stresses acting on the measurement half plane in plates 1 and 2 , as determined by neutron diffraction. The stresses acting in the longitudinal, transverse and normal orientations with respect to the welding direction are shown. Although the weld beads stand proud of the surface in both plates, this is not represented in the stress maps. Each of the contour maps for stress was produced by generating an array of data points over a $2.5 \times 2.5 \mathrm{~mm}$ spacing, using a Matlab 'v4' gridding method. ${ }^{28}$ This approach involved fitting the measured data in two dimensions using Green's functions of the biharmonic operator. ${ }^{29}$

It can be seen for both welding conditions that, in the longitudinal and transverse orientations, the highest tensile stresses correspond to locations at the HAZ boundary and also directly underneath the HAZ in adjacent parent material, rather than within the weld metal or HAZ. In the case of the longitudinal orientation, the peak stresses in both plates skirt the HAZ boundary, extending towards the top surface. Further from the weld bead, both the longitudinal and transverse stresses diminish with increasing distance from the weld bead, although both plates exhibit a region of compressive transverse stress at a depth of $12 \mathrm{~mm}$ (plate 1) and $15 \mathrm{~mm}$ (plate 2) on the centreline. As one might expect, the normal component of stress is generally low across the measurement half plane, reaching its highest levels directly underneath the HAZ. Unsurprisingly, the general features for the low (plate 1) and high (plate 2) heat input welded plates are similar. However, it can also be seen that the stress levels vary over larger length scales and greater magnitudes for the high heat input weld (plate 2).

\section{Discussion}

As a first observation, it is not surprising that the highest tensile stresses are seen over the largest regions in the longitudinal orientation, since this is the direction that corresponds to the highest contraction strain as a consequence of the welding thermal cycle. However, perhaps a more striking feature of the maps is that the stresses in the fusion zone and HAZ are significantly less tensile (or even compressive) when compared to the stresses at the HAZ boundary and in the adjacent parent plate material. This feature can arise in steels that undergo a solid state phase transformation from austenite upon cooling to either bainite or martensite. ${ }^{20,30}$ In contrast, the residual stress distributions for a similar weld configuration in an austenitic stainless steel ${ }^{31}$ have shown that, in the absence of phase transformations, the highest tensile residual stresses would be expected to arise across the fusion zone and HAZ.

Insights relating to the nature of the residual stress distributions for plates 1 and 2 are provided by the results of the Satoh tests (Fig. 7). We have seen that when coupons are heated to a peak temperature corresponding to a location near the HAZ boundary $\left(\sim 680^{\circ} \mathrm{C}\right)$ that does not undergo austenitisation, they accumulate more stress due to thermal contraction on cooling than those coupons that are austenitised during simulated welding thermal cycles. It is also apparent that when phase transformations on cooling take place at lower temperatures, the room temperature residual stresses are less tensile, since there is reduced scope for thermal contraction to occur after the transformations have exhausted. This appears to be the case regardless of whether the lower transformation temperatures are a consequence of an increased cooling rate (see Fig. 7a) or perhaps a consequence of a change in composition and an associated change in transformation kinetics (compare Fig. $7 a$ and $b$ ). Indeed, such changes in transformation temperature might explain why in the current study, where a bainitic martensitic steel has been investigated, the stresses in the fusion zone and HAZ are significantly less tensile than the peak stresses, 


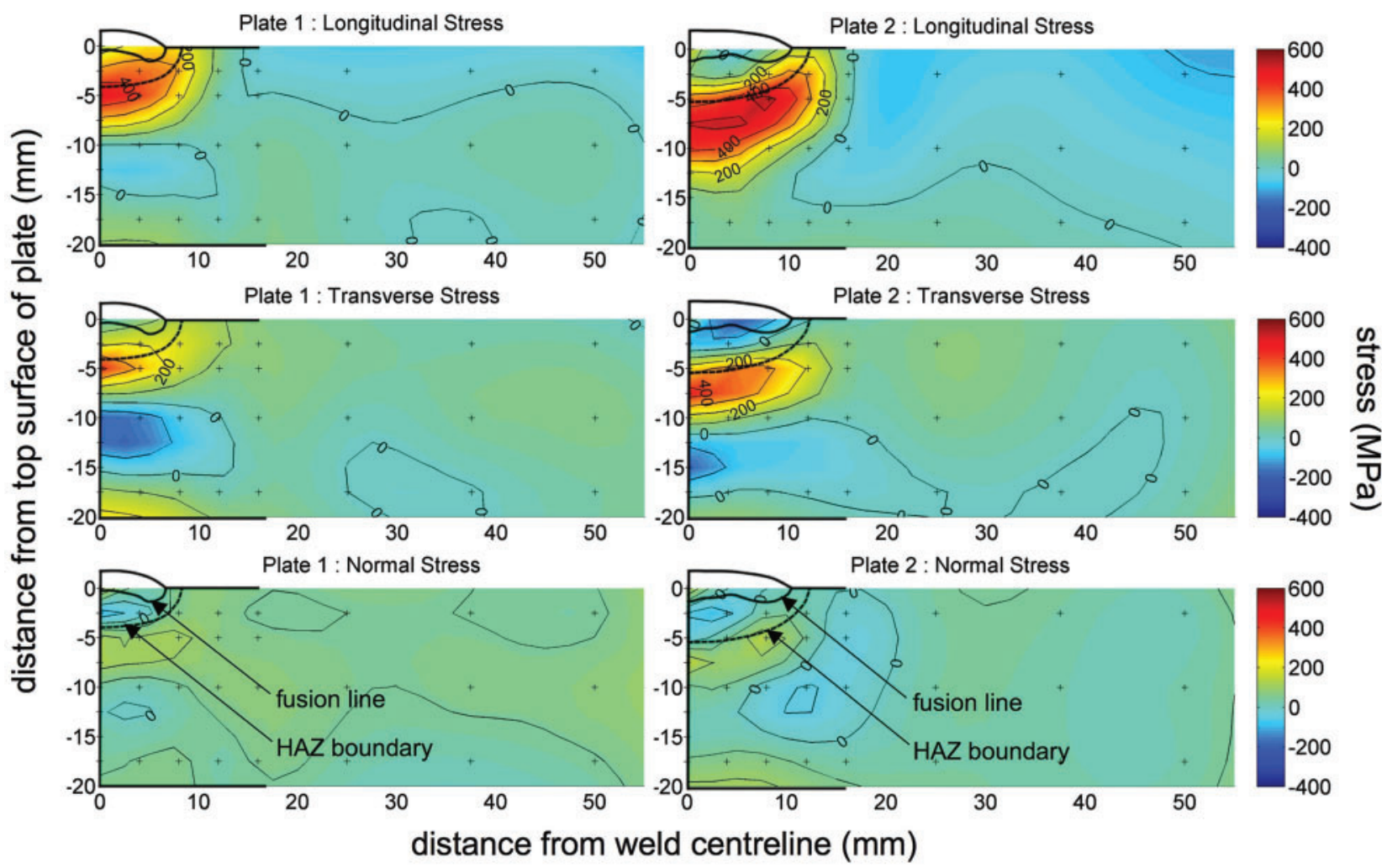

8 Contour plots for longitudinal, transverse and normal components of residual stress, as determined on measurement half plane, for low heat input weld (plate 1) and high heat input weld (plate 2): respective fusion boundaries and HAZ, as determined by metallography, have been highlighted

whereas in the work of Price et al., ${ }^{16}$ where a low alloy ferritic pearlitic steel was used, the measured stresses in and near to the fusion zone were highly tensile and comparable to the peak tensile stresses.

It is noteworthy that the results in Figs. 6 and 8 reveal that, for weld beads deposited on to SA508 steel, the location of the peak tensile stresses correlates with the location of metallurgical zones, and that the peak stresses appear to reside both at, and immediately outside, the HAZ boundary. The proximity of the peak stress region to the weld bead, and its magnitude, will therefore depend on both the extent of the HAZ and the transformation temperatures that are applicable across the HAZ, and these will vary with the weld configuration and the welding parameters. As one might expect, the higher heat input leads to a more extensive fusion/ HAZ zone in common with previous observations. ${ }^{32}$ Here this has the effect of pushing the peak tensile stresses deeper into the plate $(\sim 8 \mathrm{~mm}$ compared with $\sim 5 \mathrm{~mm}$ for the low heat input weld), and giving rise to larger longitudinal (550 $\mathrm{MPa}$ compared to $400 \mathrm{MPa}$ ) and transverse (440 MPa compared to $400 \mathrm{MPa}$ ) stresses.

While the residual stress distributions in the current study correspond to single weld passes on relatively thick plates, the findings are broadly consistent with the results presented by Dai et al., ${ }^{20}$ who interrogated low transformation temperature groove welds in $12 \mathrm{~mm}$ thick plates, for which the HAZ extended through the plate thickness. In that case the low stress region also extended throughout the fusion and into the HAZ, with the highest tensile stresses being pushed laterally outwards from the centreline and appearing to reside both at and just beyond the HAZ/parent plate boundary.
Finally, the residual stress distributions reveal one or two other features that are noteworthy. The trends in the measurements beyond the HAZ agree with those of Lin and Lee, ${ }^{32}$ who found larger peak stresses at higher heat inputs, as recorded by hole drilling $5.5 \mathrm{~mm}$ from the fusion line. Perhaps curiously though, the higher heat input condition appears to have lower stresses in the fusion zone itself. It is plausible that this is an artefact of the measurement process, in that for the lower heat input (plate 1), the weld bead is smaller and the local stress and microstructure gradients steeper. As such, the neutron diffraction gauge volume may have simultaneously sampled material from both the fusion zone and parts of the HAZ that were subjected to higher levels of stress when measuring at this location. This would have had the overall effect of increasing the apparent stress in the fusion zone. Finally, while both welds do show low level tensile transverse stresses on the weld line at the bottom surface of the plate, indicative of the bending (butterfly distorting) stresses normally introduced by the contraction of weld metal in partially penetrating ' $\mathrm{V}$ ' welds, they are smaller than might normally be expected. ${ }^{33}$ This corroborates the thesis that the transformation has offset the thermal contraction thereby reducing the bending stresses. This is further supported by the fact that the tensile transverse stresses for the high input weld are smaller on the bottom face than for the low input weld, despite the greater extent of the thermal excursion.

\section{Potential implications for weld integrity}

The potential for cracking during cooling after welding, and the development of low toughness microstructures 
in either the weld metal or HAZ, are of significant concern in structural integrity assessments. The coarse grained HAZ, for example, is particularly susceptible to hydrogen cracking, and the integrity of steel welds can often be compromised by the low toughness that can result in this zone. While these concerns apply to steel welds in general, in the context of SA508 steel the toughness of the coarse grained HAZ is known to be an issue for transition joints between a reactor pressure vessel and the associated cooling circuit. ${ }^{34}$

Given the possibility of forming low toughness microstructures in different locations across a weldment, it would seem desirable to avoid the possibility of developing the highest tensile residual stresses in either the weld metal or HAZ. In the present study the authors have found that the relatively low transformation temperature of SA508 steel upon cooling from austenite results in the location of the highest tensile residual stresses being shifted from the weld metal and the vulnerable CGHAZ region to the HAZ boundary, i.e. to material that resides immediately outside those regions that have either fully or partially austenitised during welding. This may translate to significant benefits for the integrity of welds, since the tempered zone and parent material will usually have a higher toughness (and exhibit less variability in toughness) when compared to other regions in a welded joint.

While the relatively low transformation temperatures associated with SA508 steel may result in what might be expected to be desirable residual stress distributions around a single weld bead, further work and testing are clearly required to establish whether these distributions do indeed result in improved weld performance. Another priority for researchers would appear to be an examination of residual stress evolution in multipass welds, where multiple thermal cycles may lead to a more complex relationship between microstructural zones and the levels of residual stress.

\section{Conclusions}

When a single weld bead is deposited onto an SA508 reactor pressure vessel steel plate, the highest tensile stresses arise not within the weld bead or CGHAZ, but at the HAZ boundary and in adjacent parent material, i.e. immediately outside those regions that have either fully or partially austenitised during welding. Such a residual stress distribution may reduce the susceptibility of single pass welds in SA508 steel to hydrogen (cold) cracking, and cracking in the fusion zone and CGHAZ more generally.

The results of Satoh tests indicate that the reduced tensile residual stresses in the fusion zone and austenitised regions within the HAZ can be explained in terms of the effects of solid state phase transformations on cooling after welding. That is, if the transformation temperature upon cooling is sufficiently low, then the transformation strain can compensate to a significant extent for the thermal contraction strain, leaving substantially lower room temperature residual stresses in the transformed zone.

The effects of heat input on the location and size of the regions in which the highest tensile residual stresses reside appear to relate to the spatial distribution of peak temperature during the welding thermal cycle, and any effect that the cooling rate might have on the local transformation temperature in each zone upon cooling. In the present study, an increase in heat input resulted in: larger longitudinal and transverse tensile stresses at the HAZ boundary and in adjacent parent material, due to the more extensive thermal excursion; the peak tensile stress region being located further from the weld bead in line with a larger HAZ.

Further work, especially with regard to mechanical performance, is required to establish whether a shift in the location of the highest tensile residual stresses from the fusion zone and CGHAZ to the HAZ boundary and adjacent parent material does indeed translate to improved weld integrity. In addition, it is necessary to investigate whether any potential benefits for weld integrity are likely to translate to multipass welds, where additional complexity is introduced by multiple thermal cycles.

\section{Acknowledgements}

This research project has been supported by the European Commission under the 6th framework programme through the key action: Strengthening the European Research Area, Research Infrastructures (contract no. RII3-CT-2003-505925). The allocation of beam time on the STRESS-SPEC instrument at Forschungsneutronenquelle Heinz Maier-Leibnitz (FRM II) and on the SALSA instrument at the Institute Laue-Langevin (ILL) are also gratefully acknowledged.

The authors would like to thank Dr J. Rebelo Kornmeier and Dr R. C. Wimpory for assistance at FRM II, and Dr T. Pirling and Dr D. J. Hughes for assistance at ILL. The authors are indebted to Dr H. Dai, Dr S. A. McDonald, Dr L. I. Pocock and Dr J. F. Kelleher at the University of Manchester for assistance with the neutron diffraction measurements. The authors are also grateful for support from Rolls-Royce Marine, and in particular would like to acknowledge valuable discussions with Dr C. T. Watson, P. R. Hurrell and C. Gill, as well as S. K. Bate at Serco Assurance.

\section{References}

1. P. J. Withers: Rep. Prog. Phys., 2007, 70, (12), 2211-2264.

2. D. J. Hornbach and P. S. Prevey: J. Press. Vess. Techn., 2002, 124, (3), 359-365.

3. M. Turski, P. J. Bouchard, A. Steuwer and P. J. Withers: Acta Mater., 2008, 56, (14), 3598-3612.

4. P. J. Bouchard, P. J. Withers, S. A. McDonald and R. K. Heenan: Acta Mater., 2004, 52, (1), 23-34

5. X. H. Cheng, J. W. Fisher, H. J. Prask, T. Gnaupel-Herold, B. T. Yen and S. Roy: Int. J. Fatig., 2003, 25, (9-11), 1259-1269.

6. W. Fricke: Materialwiss. Werkst., 2005, 36, (11), 642-649.

7. D. P. G. Lidbury: Int. J. Press. Vess. Pip., 1984, 17, (4), 197-328.

8. D. T. Read: Eng. Fract. Mech., 1989, 32, (1), 147-153.

9. R. A. Ainsworth, J. K. Sharples and S. D. Smith: J. Strain Anal. Eng. Design, 2000, 35, (4), 307-316.

10. R. A. Ainsworth: Int. Mater. Rev., 2006, 51, (2), 107-126.

11. Y. Lei, N. P. O'Dowd and G. A. Webster: Int. J. Fract., 2000, 106, (3), 195-216.

12. P. J. Withers and H. K. D. H. Bhadeshia: Mater. Sci. Technol., 2001, 17, (4), 355-365.

13. P. J. Withers and H. K. D. H. Bhadeshia: Mater. Sci. Technol., 2001, 17, (4), 366-375.

14. J. A. Francis, H. K. D. H. Bhadeshia and P. J. Withers: Mater. Sci. Technol., 2007, 23, (9), 1009-1020.

15. D. J. Smith, P. J. Bouchard and D. George: J. Strain Anal. Eng. Design, 2000, 35, (4), 287-305.

16. J. W. H. Price, A. Paradowska, S. Joshi and T. Finlayson: Int J. Press. Vess. Pip., 2006, 83, 381-387.

17. K. Satoh: Trans. Jpn Weld. Soc., 1972, 3, 125-134. 
18. K. Satoh: Trans. Jpn Weld. Soc.y, 1972, 3, 135-142.

19. K. Suzuki, I. Kurihara, T. Sasaki, Y. Koyoma and Y. Tanaka: Nucl. Eng. Design, 2001, 206, 261-278.

20. H. Dai, J. A. Francis, H. J. Stone, H. K. D. H. Bhadeshia and P. J. Withers: Metall. Mater. Trans. A, 2008, 39A, (13), 3070-3078.

21. H. Cho and I. S. Kim: Mater. Sci. Forum, 2005, 475-479, 4121-4124.

22. A. D. Krawitz and R. Winholtz: Mater. Sci. Eng. A, 1994, A185, (1-2), 123-130.

23. P. J. Withers, M. Preuss, A. Steuwer and J. W. L. Pang: J. Appl. Crystall., 2007, 40, 891-904.

24. S. L. Mannan and K. Laha: Trans. Ind. Inst. Met., 1996, 49, (4), 303-320.

25. H. K. D. H. Bhadeshia and R. W. K. Honeycombe: 'Steels microstructure and properties', 3rd edn, 287-306; 2006, Oxford, Butterworth-Heinemann.

26. Ø. Grong: 'Metallurgical modelling of welding', 2nd edn, 504-506; 1997, London, The Institute of Materials.
27. M. V. Li, D. V. Niebuhr, L. L. Meekisho and D. G. Atteridge: Metall. Mater. Trans. B, 1998, 29B, (3), 661-672.

28. MATLAB, version 7.2 (R2006a), The Math Works, Inc., Natick, MA, USA, 2006.

29. D. T. Sandwell: Geophys. Res. Lett., 1987, 14, 139-142.

30. J. A. Francis, H. J. Stone, S. Kundu, R. B. Rogge, H. K. D. H. Bhadeshia, P. J. Withers and L. Karlsson: J. Press. Vess. Technol., to be published.

31. Y. Zhang, S. Pratihar, M. E. Fitzpatrick and L. Edwards: Mater Sci. Forum, 2005, 490-491, 294-299.

32. Y. C. Lin and K. H. Lee: J. Mater. Process. Technol., 1997, 63, (13), 797-801.

33. D. J. Hughes, P. J. Webster and G. Mills: Mater. Sci. Forum, 2002 , 404-407, 561-566.

34. A. Laukkanen, P. Nevasmaa, U. Ehrnstén and R. Rintamaa: Nucl. Eng. Design, 2007, 237, (1), 1-15. 